\title{
Rémi DALISSON, Célébrer la nation. Les fêtes nationales en France de 1789 à nos jours
}

\section{Franck Laidié}

\section{(2) OpenEdition}

\section{Journals}

Édition électronique

URL : https://journals.openedition.org/ahrf/12182

DOI : $10.4000 /$ ahrf.12182

ISSN : $1952-403 X$

Éditeur :

Armand Colin, Société des études robespierristes

Édition imprimée

Date de publication : 1 septembre 2011

Pagination : 221-223

ISBN : 978-2-200-92700-4

ISSN : 0003-4436

Référence électronique

Franck Laidié, "Rémi DALISSON, Célébrer la nation. Les fêtes nationales en France de 1789 à nos jours », Annales historiques de la Révolution française [En ligne], 365 | Juillet-septembre 2011, mis en ligne le 13 décembre 2011, consulté le 24 avril 2022. URL : http://journals.openedition.org/ahrf/12182 ; DOI : https://doi.org/10.4000/ahrf.12182

Ce document a été généré automatiquement le 24 avril 2022

Tous droits réservés 


\title{
Rémi DALISSON, Célébrer la nation. Les fêtes nationales en France de 1789 à nos jours
}

\author{
Franck Laidié
}

\section{RÉFÉRENCE}

Rémi DALISSON, Célébrer la nation. Les fêtes nationales en France de 1789 à nos jours, Paris, Nouveau monde éditions, 2009, 453 p., ISBN 978-2-84736-324-1, $24 €$.

1 Avec son nouvel ouvrage Célébrer la nation. Les fêtes nationales en France de 1789 à nos jours, Rémi Dalisson vient combler un vide historiographique. En effet, si la fête nationale a déjà fait l'objet de travaux remarquables sur des périodes plus ciblées, aucune étude d'une telle ampleur chronologique n'a été jusqu'alors réalisée.

Il convient bien évidemment de saluer ici l'ambition de Rémi Dalisson. Cette ambition se justifie pleinement au regard de l'acuité des interrogations actuelles sur l'identité nationale, sur les questions mémorielles, sur les exploitations politiques qui en sont faites et le travail de l'historien. L'auteur reprend ici des thématiques de recherches qui lui sont chères et qui ont donné lieu déjà à deux publications: Les trois couleurs, Marianne et l'empereur : fêtes libérales et politiques symboliques en France, 1815-1870 (Paris, La Boutique de l'histoire, 2004) ainsi que Les fêtes du maréchal: propagande festive et imaginaire dans la France de Vichy (Paris, Tallandier, 2008). En élargissant le champ chronologique de ses études aux fêtes nationales sur le long terme, l'auteur veut appréhender cette " culture de la fête ", spécificité française qui a "pu à la fois souder le pays autour de ses dirigeants, incarner la nation, être objet de contestation, et en définitive, servir de repère identitaire aux Français ». Il s'agit par-delà l'ensemble des régimes qui se succèdent depuis 1789 jusqu'à la cinquième République de rechercher nouveautés, continuités et ruptures qui vont accompagner l'évolution des célébrations nationales. 
3 L'ouvrage de Rémi Dalisson s'organise en six chapitres successifs - Des fêtes civiques de la Révolution au culte personnel de «Napoléon le Grand» (1789-1814); L'impossible restauration culturelle et la matrice des fêtes du «roi des Français» (1814-1848); L'ébauche du culte de Marianne et le syncrétisme des fêtes du second Empire; Le 14 juillet et ses petites sœurs : âge d'or et mutation de la fête républicaine moderne (1870-1940); Philippe contre Marianne: Les fêtes vichystes ou la fausse rupture (1940-1944); La fête républicaine en miettes : de l'illusion de la Libération aux querelles mémorielles (1944 à nos jours). Cette construction qui, d'une façon chronologique, pose la question de la fête nationale, rend bien compte de ses évolutions et ses permanences. Elle facilite la démonstration de l'auteur et renforce le plaisir de la lecture. L'on peut cependant regretter le traitement trop rapide réservé à la fête révolutionnaire. L'auteur lui-même rappelle à de nombreuses reprises ses caractères spécifiques, didactique, pédagogique, qui contrastent avec les célébrations des régimes suivants. La régénération et la formation d'un homme nouveau dans un régime nouveau méritent sans doute un traitement particulier ou pour le moins de faire davantage ressortir les ruptures qui s'imposent à la fin de la décennie révolutionnaire, au-delà d'un nombre finalement limité d'héritages républicains. Le foisonnement inégalé des débats révolutionnaires sur les fêtes, notamment dans les projets d'éducation nationale et d'instruction publique, est également trop négligé. D'autant que ce modèle révolutionnaire reste pour les étapes suivantes l'exemple ou le contre-exemple.

Quelques imprécisions viennent troubler le lecteur pour cette période essentielle et fondatrice. Il est surprenant d'évoquer les propos du préfet de Bourges lors de la fête du 10 août 1793 ou le rapport du préfet de Seine-et-Oise à propos de la fête de la souveraineté du peuple de 1798 , alors que l'institution de la préfecture résulte de la grande loi du 28 pluviôse an VIII. Plus grave peut-être, toujours pour la période révolutionnaire, l'auteur se contente de renvoyer pour les fêtes provinciales aux seuls travaux de Michel Vovelle et "plus généralement [de] voir les articles consacrés au sujet dans les Annales historiques de la Révolution Française " sans autres précisions. On peut s'étonner de ne pas trouver dans l'appareil critique, au-delà des références incontournables et classiques mais déjà anciennes sur la fête révolutionnaire, un certain nombre de travaux plus récents. Certains de ces ouvrages, collectifs, mériteraient sans aucun doute d'être utilisés par l'auteur. Ils permettent en effet d'accéder à « cette littérature grise » hélas trop souvent destinée à demeurer oubliée, que constituent les mémoires de maîtrise et de master retravaillés dans ces communications. D'autres disciplines, dont l'histoire du droit, se sont saisies de la question des fêtes révolutionnaires et sont venues compléter l'historiographie festive révolutionnaire. Cela aurait pu être intéressant, sur le fond, par exemple pour comprendre la fête des époux; ce n'est pas d'un «attachement à la morale la plus traditionnelle » dont il est question alors. Il s'agit de faire passer dans les populations les modifications substantielles apportées au mariage devenu un contrat civil laïcisé par la loi du 20 septembre 1792. Le mariage est le symbole de la liberté individuelle mais aussi l'acte fondateur du nouvel ordre social et moral né de la Révolution.

5 Tout au long de l'ouvrage, pour l'ensemble des périodes étudiées, quelques difficultés méthodologiques sont à évoquer. Trop souvent les références des sources sont absentes quand l'auteur évoque certains discours, célébrations ou rapports préfectoraux. Parallèlement, il est dommageable aux démonstrations de l'auteur qu'à aucun moment le lecteur ne soit informé de la réalité du corpus des sources - visiblement très riche 
pourtant - utilisées par Rémi Dalisson et de la façon dont elles ont été exploitées. Que vaut un pourcentage de célébrations, d'incidents, de non-célébrations si l'on ne sait pas comment il est calculé, si l'on ne sait pas à quelle réalité géographique, territoriale et humaine il se rapporte? Le lecteur reste ici livré à lui-même. Enfin, l'annonce du préfacier d'« une rencontre de la fête dans toute sa richesse et sa diversité territoriales dans les petites et grandes villes de province jusqu'aux coins les plus reculés de l'hexagone » reste sans effet. On espère, on attend et pourtant jamais vraiment on ne rencontre cette fête célébrée au plus près des Français. Ces célébrations sont pourtant précieuses et irremplaçables même si certains auteurs ont pu quelquefois considérer leurs relations dans les sources comme désincarnées. On ne peut donc que regretter ce parti pris de l'auteur de négliger l'échelle locale indispensable pour mieux appréhender cette « sociabilité locale » que lui-même évoque.

6 Au-delà de ces réflexions critiques et de ces réserves méthodologiques, on ne peut que se féliciter de l'ouvrage de Rémi Dalisson, qui projette la fête nationale sur le temps long. Cette étude est désormais un instrument préalable, incontournable, pour toute personne désirant s'intéresser à la question de la fête nationale. On y retrouve jusque dans les annexes une foule d'informations précieuses sur cette "culture de la fête", qu'aucun régime depuis 1789 n'a jamais remise en question. 